\title{
International Student Academic Performance: Some Statistical Evidence And Its Implications
}

Yunke He, Okanagan College, Canada

Heather Banham, Okanagan College, Canada

\begin{abstract}
Using time series data, this study shows that domestic students' academic performance is generally better than international students' performance, but the gap is significantly narrowing as international students' performance is improving over time. The study also shows that there is no strong correlation between the percentage of international students in the student body and the international or domestic student performance during the limited study period. Contributing factors to, and policy implications of, the research outcomes are also discussed.
\end{abstract}

Keywords: International students, domestic students, academic performance, education, academic administration, teaching, grade average, School of Business

\section{INTRODUCTION}

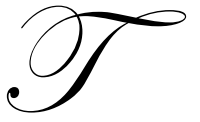

he academic performance of international students is of interest to academic institutions in relation to the allocation of resources to internationalization initiatives; international recruiting teams (as their performance is frequently measured on the basis of contribution to the overall institution); international students themselves as they select an educational destination; and professors in programs which have international students. While anecdotally the view is expressed that international students do not perform as well as domestic students, there is some evidence to the contrary in the literature. Where the strategic plan of the institution includes the development of a strong international student presence, there is an imperative to determine the drivers of student success (Harnett, Romcke and Yap, 2003). Okanagan College in Kelowna, British Columbia, Canada is in exactly this situation. This research is aimed at providing a better basis for internal decision making in relation to recruitment and support to international students and at the same to contribute to the literature on international student success.

\section{BACKGROUND}

The Okanagan School of Business at Okanagan College transitioned from the Faculty of Business at Okanagan University College in June 2005. Its flagship program is the Bachelor of Business Administration (BBA) which has specializations in Accounting, Financial Services, Hospitality and Tourism Management, Human Resources Management, Management and Marketing. International students attending Okanagan College are able to take English for Academic Purposes (EAP) and on attaining prescribed proficiency are able to commence their academic course work concurrently with their EAP program.

The "Key Directions" of Okanagan College, as presented in the Strategic Plan 2005, include the following on "Cultural and Social Diversity":

Prepare students to excel in an increasingly inter-dependent and culturally diverse global environment:

- $\quad$ Increase cultural and social diversity in curriculum and campus activities 
- Increase international activity in all four regions

- Increase international student satisfaction with facilities, services, programs and campus life

- Increase the number of Okanagan College students who engage in study abroad activities.

This research is significant for the institution in meeting these key directions and in relation to recruitment of international students, placement within programs, and is especially significant for the Okanagan School of Business as the majority of international students are planning to get a business education. It is also important to note that internationalization at the Okanagan School of Business is driven by joint imperatives - that of ensuring both domestic and international students are prepared with multi-cultural communication skills for the world of business as well as generating revenues from differential tuition fees paid by international students.

In an internal review of the success of students completing EAP courses concurrently with business courses (Smith, Cooke and Gilchrist, 2008) the following statements were made in relation to the academic success of students:

Level 4 students are not eligible to take Business courses except for the Business 111 course which is Financial Accounting and is math based. The rationale is that the students have adequate math background and language is not as necessary in this course. However, the statistics reveal otherwise. The failure rate for Level 4 students is $40 \%$. The rate for non-ESL students is 13.6\%. (Authors' Note: Students at Level 4 will no longer be able to concurrently register in BuAd 111 as they complete their English language requirements for entry into the academic program.) results:

Other Business courses that have been taken when students have reached Level 6 have the following

- $\quad$ BuAd 176 Professional Selling taken by 10 students at Level 6 has a passing rate of $80 \%$.

- $\quad$ BuAd 272 Business Simulation taken by 19 students at Level 6 has a passing rate of 94.7\%.

- $\quad$ BuAd 293 Entrepreneurship taken by 24 students at Level 6 has a passing rate of 83.3\%.

Non Business courses that are required as part of the BBA program show the following results:

- $\quad$ Econ 125 Principles of Macroeconomics taken by 18 students at Level 5 has a passing rate of $78 \%$ and the results for ESL and non-ESL do not differentiate greatly.

- $\quad$ Stats 121 Elementary Statistics was taken by 16 students at Level 6 has a passing rate of 93.8\%. Non-ESL students have a pass rate of $80.8 \%$.

- $\quad$ Stats 124 Business Statistics taken by 47 students at Level 6 has a passing rate of 80.9\% and non-ESL students have a pass rate of 80.8\%' (Smith, Cooke and Gilchrist, 2008).

Pass rates in both business and non-business courses are acceptable. However, in most situations the domestic students have stronger pass rates but ESL students demonstrate higher levels of academic achievement in Stats 121 Elementary Statistics than their domestic contemporaries.

\section{LITERATURE REVIEW}

There is very limited literature referencing international student academic performance. An extensive search using key words for ABI/inform (4,000 journals) and Academic Search Premier (4,500 journals) resulted in the identification of a gap in the research relating to this subject. In reviewing the literature it is important to note that international students are sometimes referred to as "foreign" students. While the term "foreign" is considered culturally unacceptable in Canada today, the word does appear in some of the early literature and some of the literature in countries where it is not considered to be politically incorrect. The literature review remains consistent with the word selection of the authors and researchers quoted. 
As far back as 1976 the case study on the academic performance of Norwegian students at British Universities determined that while there was a generalization that foreign students did not perform as well as the domestic students in British universities, the Norwegian students actually had a lower failure rate than their British contemporaries (Bie, 1976). An examination of international student performance in tertiary-level accounting at the University of Newcastle in Australia determined that there was no significant difference between the performance of international and resident students. In addition there was no evidence of an acculturation effect as student performance did not improve over time, (Harnett, Romcke and Yap, 2003).

When analyzing the results of post graduate students, an Australian study found that students with higher levels of English proficiency were achieving higher GPA scores (Hartnett, Romcke and Yap, 2003), while Lebcir, Wells and Bond (2008) found that teaching style, English language and communication and assessment methods were important drivers of the academic performance of international students in project management in the British university context of the study. After conducting an analysis of graduates from masters programs, the study at Macquarie University in Sydney, Australia, found that higher levels of English proficiency were related to higher GPA scores (Eddey and Baumann, 2008).

In relation to cultural bias in the assessment of learning in multi-cultural educational settings, the cultural equivalence properties of assessment methods were explored and conclusion reached that assessment by examination penalizes international students beyond differences in ability levels (deVita, 2002).

There is limited literature available on the academic performance of international students. The conclusion that little is known about the factors contributing to the academic performance of international students has also been expressed (Lebcir, Wells and Bond, 2008). The institutional context of the case studies and articles makes it very difficult to apply prior research results to specific situations because institutional strategies, learning environments and community contexts all have potential impact on the adjustment and academic performance of international students. There is a gap in the literature in relation to optimal percentages of international students to maximize the highest potential for academic performance of both the international students and the domestic students. In addition, the results of some studies, for example on the effect of acculturation are not consistent across institutional environments. This research is undertaken to inform decisions on entry requirements as well as the determination of appropriate admission policies for international students.

\section{RESEARCH QUESTIONS}

To examine the international student academic performance at the Okanagan School of Business, six research questions are formulated:

1. Is the academic performance of international students improving over time?

2. Is the academic performance between domestic and international students different?

3. Is there a correlation between the percentage of international students in the student body and their academic performance?

4. Is there a correlation between the percentage of international students in the student body and the academic performance of domestic students?

5. Is there a correlation between the percentage of international students in the student body and their academic performance in certain courses with a relatively large international enrolment?

6. Is there a correlation between the percentage of international students in the student body and the academic performance of domestic students in certain courses with a relatively large international enrolment?

The process to address the research questions is depicted in Figure 1, which shows data collection, time series analysis, and comparisons of results. 
Figure 1 Outline of the Research

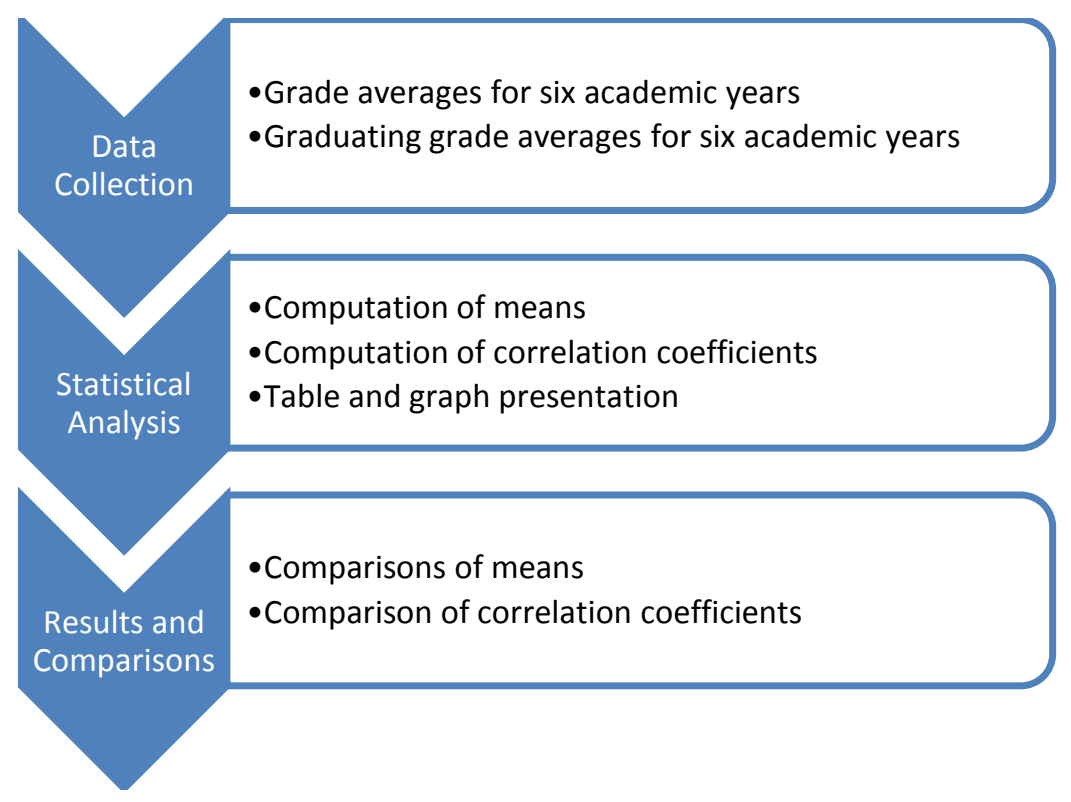

The data is described in the next section.

\section{DATA}

The research questions are examined in relation to international students attending the Okanagan School of Business at Okanagan College. Academic performance data of business students has been used in the analysis. The data has been gathered over a six-year time period from the 2002-2003 to 2007-2008 academic years. For convenience in this analysis, we redefine this time period as Year 1 to Year 6. Four data sets are described as follows:

1. Business Graduation Grades contain every academic grade achieved by students who graduated from the Okanagan School of Business in the Business Administration Diploma (BuAd) program or the BBA degree program. The data is recorded from admission to the point of meeting graduation requirements.

2. Business Graduation Averages contain one line for each BuAd and BBA graduate, showing the Grade Average (GA), Graduating Grade Average (GGA), and other demographic information.

At Okanagan College GA is defined as the weighted average of grades for all courses taken. The method for calculation GA is to multiply each course credit value by the standard percentage grade received, add the weighted grades, and divide the sum by the total number of credit hours.

GGA is defined as the weighted average of grades for those courses taken at the College to satisfy the graduation requirements for a degree, associate degree, diploma, or certificate. Specifically, in the BBA degree program GGA is based on grades for the last 60 credits used to satisfy graduation requirements; in associate degree, diploma and certificate programs, GGA is based on the grades of all courses taken at Okanagan College for credit towards satisfying the graduation requirements.

3. Business Section Grades contain every grade assigned to a business course section.

4. Business Section Averages contain one row per business course section, showing domestic and international headcounts and related grade averages. 
At Okanagan College there are unique student number identifiers for international and domestic students. 300 series student identification numbers are assigned to domestic students and 800 series student identification numbers are assigned to international students (this relates to Years 1,2 and 3 in the data sets).

Some international students are granted permanent resident status during their years of study at the college. As a result, these students who have a change in status have 300 series student identification numbers at graduation. It would not serve our research objective well if we solely rely on 800 series student numbers to identify international students. Therefore we reclassify these students as international students.

Each year the Okanagan School of Business has a number of incoming international exchange students from partner institutions located in various countries around the world. These students are also assigned the unique international student number identifiers. Some of these students are from countries where English is their first language; some are from countries where even though English is not their first language it is a very strong second language, and others are from countries where English is not so strongly incorporated into the educational system. Because of the potential to impair the results, the exchange students are completely excluded from the analysis.

\section{METHODOLOGY}

The methodology employed to address the research questions included data collection for a six year period of GA and GGA for students in the Okanagan School of Business. Time series analysis is undertaken as a preliminary step. Statistical comparisons of means and the calculation of correlation coefficients is undertaken to understand the data in relation to the research questions. Table 1 shows the International Headcount and percentage of students in the Okanagan School of Business overall.

Table 1 International Headcount and Percentage of Students in the Okanagan School of Business

\begin{tabular}{|lccccccc|}
\hline & Year 1 & Year 2 & Year 3 & Year 4 & Year 5 & Year 6 \\
\hline International Headcount & 120 & 120 & 206 & 224 & 270 & 339 \\
\hline International Headcount (\%) & 2.5 & 1.667 & 9.2233 & 13.3929 & 10.3704 & 10.9145 \\
\hline
\end{tabular}

It is highly probable that the higher percentage of international students in Year 4 was skewed by the fact that students entering the Okanagan School of Business in that year were guaranteed a co-conferred BBA degree by University of British Columbia - Okanagan and Okanagan College.

\section{RESULTS AND DISCUSSION}

Using the above data, various averages and correlation coefficients are computed, and graphs are drawn, in order to answer the six research questions.

\section{Research Question 1}

Is the academic performance of international students improving over time?

Using the Business Grade Average data, the annual averages of both GA and GGA for international students are computed. The grade percentages are shown below in Table 2, GAs range between 66.26 and 71.71 percent while GGAs range between 68.5 and 75.35 per cent.

Table 2 International Student Performance

\begin{tabular}{|lllllll|}
\hline & Year 1 & Year 2 & Year 3 & Year 4 & Year 5 & Year 6 \\
\hline GA & 71.57 & 66.26 & 69.87 & 68.30 & 69.00 & 71.71 \\
\hline GGA & 75.35 & 68.50 & 72.56 & 70.92 & 71.38 & 73.86 \\
\hline
\end{tabular}



points.

Figure 2 presents GA data graphically. Note that the data has a total range of approximately 5.5 percentage

Figure 2 International Students' Performance (GA)

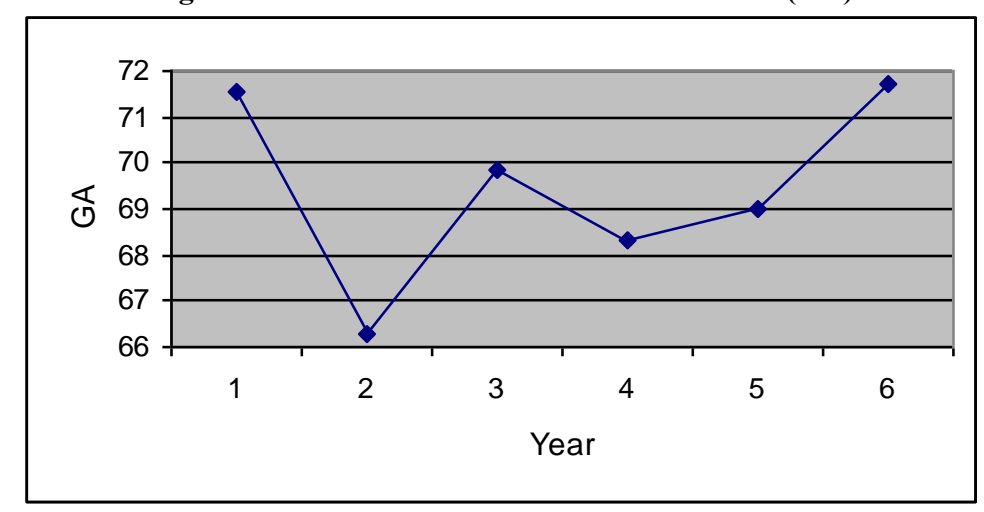

Figure 3 presents GGA data graphically. Note that over the six years of the study the data has a total range of 6.85 percentage points.

Figure 3 International Students' Performance (GGA)

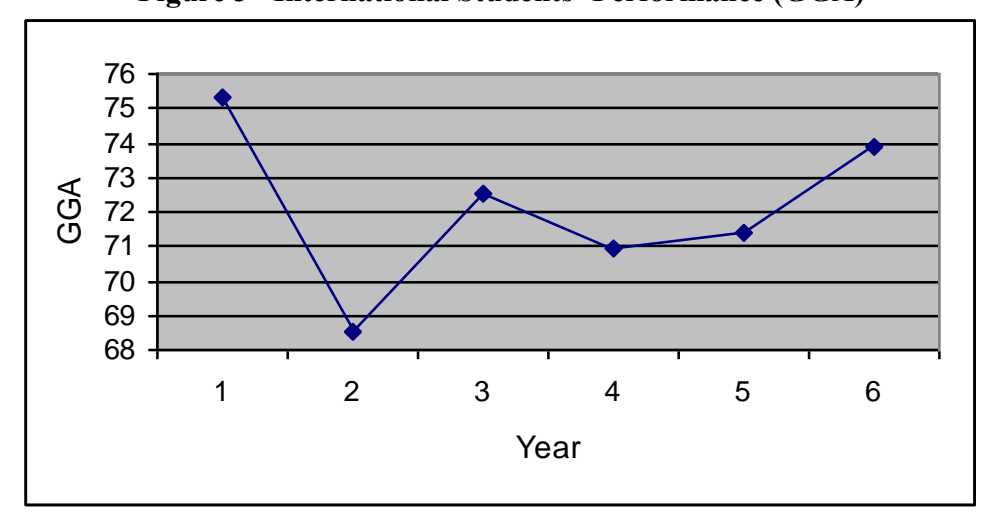

The number of international students in the Okanagan School of Business in Years 1 and 2 is quite low and represents only a very small percentage of the total headcount, therefore the results for those two years need to be interpreted in this context. In attempting to understand the fluctuations evident in the data it is interesting to note that the drop in GA and GGA for both international and domestic students coincides with the year of the announcement on the major restructuring of post secondary education in the Province of British Columbia. This restructure had a profound implication in the Okanagan region as Okanagan University College was transitioned into two institutions: University of British Columbia - Okanagan and the new Okanagan College. It is entirely understandable that students became very concerned about the quality of their education, the impact on their program and the costs of education in the new institutions.

GA and GGA for international students are showing improvement over Years 4, 5 and 6. Year 4 is the first year of the newly formed Okanagan College. It is also interesting to note that GGA is consistently higher than GA in each year. Perhaps this indicates that the students focused on credential completion (both the Business Administration Diploma and the BBA degree). It may also be reflective of the efforts undertaken by the Okanagan School of Business and Okanagan College in support of the strategic vision to build a learner-centered organization 
dedicated to student success and to embrace internationalization. The initiatives undertaken have included workshops and materials on successful approaches to teaching international students, establishment of a learning center and employment of tutors (including student tutors), to be available to assist students. The Okanagan School of Business and International Education Department have worked collaboratively to build supporting infrastructure to enhance student success.

The results show that GGA is consistently higher than GA. This can be partly attributed to the fact that all first year courses are included in GA. Students gain a greater level of mastery of the English language as time progresses. Also as students progress through the programs they are more familiar with the support services available to them and are able to access them in a more timely manner. This is an area for future research as stronger substantiation could potentially lead to new initiatives to fast track language skills and specific initiatives to increase awareness of support services.

Another contributing factor may be the process of acculturation as students become more familiar with the structure and terminology of the business environment in Canada, thus gain a fuller understanding for their business studies. The first year includes a large adjustment process and by Years 2, 3 and 4 international students are more familiar with the social environment and have established better social support.

Based on the data and the analysis above, Research Question 1 has been answered: the academic performance of international students is improving over time.

\section{Research Question 2}

Is the academic performance between domestic and international students different?

Using the Business Graduation Averages data, yearly averages of both GA and GGA for international and domestic students are computed. The results are shown below in Table 3. Over the six years of the study, the international GA is reported lower than the domestic GA. The difference ranges from 5.65 percentage points of difference in Year 2 to 0.64 percentage points of difference in Year 6.

Conversely GGA data shows that international students outperformed domestic students by 0.57 percentage points in Year 1. The domestic GGA is higher in the other five years and the percentage points of difference range from 4.93 in Year 2 to 0.89 in Year 6.

Table 3 International and Domestic Student Performance

\begin{tabular}{|lccccccc|}
\hline & Year 1 & Year 2 & Year 3 & Year 4 & Year 5 & Year 6 \\
\hline International GA & 71.57 & 66.26 & 69.87 & 68.30 & 69.00 & 71.71 \\
\hline Domestic GA & 73.80 & 71.91 & 72.97 & 72.95 & 72.81 & 72.45 \\
\hline International GGA & 75.35 & 68.5 & 72.56 & 70.92 & 71.38 & 73.86 \\
\hline Domestic GGA & 74.88 & 73.47 & 75.18 & 75.17 & 75.06 & 74.75 \\
\hline
\end{tabular}

Figure 4 International and Domestic Student Performance (GA)

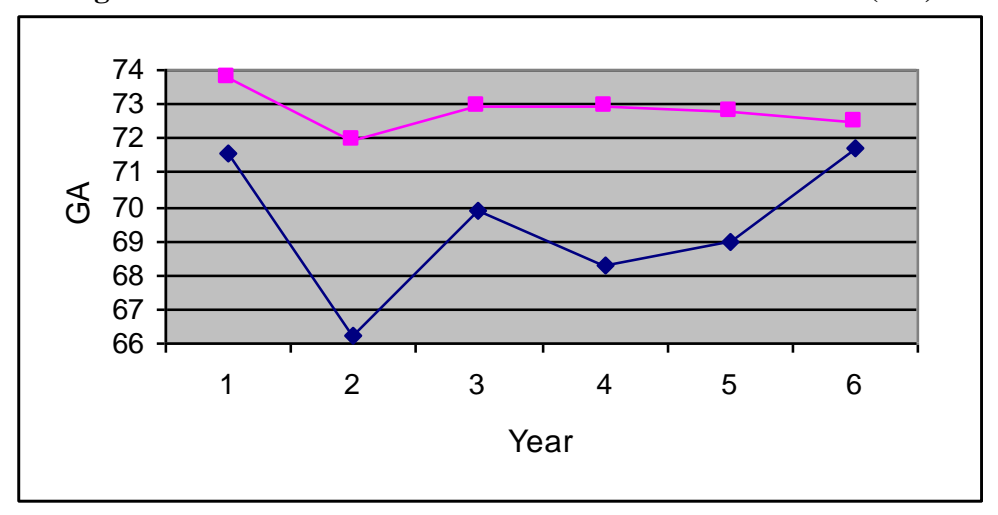


Figure 4 presents GA data graphically and it is interesting to note that the pattern is mirrored in Years 1, 2 and 3, while Years 4 and 5 show independent movement with the data for Year 6 moving to a very narrow range of difference between international and domestic grades. The data for Years 1,2 and 3 were recorded when the institution was Okanagan University College and in Years 4, 5 and 6 the same program was at the newly formed Okanagan College.

Figure 5 presents GGA data graphically for the six years and shows the very narrow differences in performance in Year 1 when international GGA was higher than domestic GGA and again in Year 6 when domestic GGA was slightly higher than international GGA. Domestic students consistently outperform international students and this can be attributed to the language issue as well as the fact that domestic students have a better knowledge of their home country particularly in relation to political, economic and business environment that is very relevant to business curriculum. Domestic students are also in a familiar social environment and normally have a social support system intact.

Figure 5 International and Domestic Student Performance (GGA)

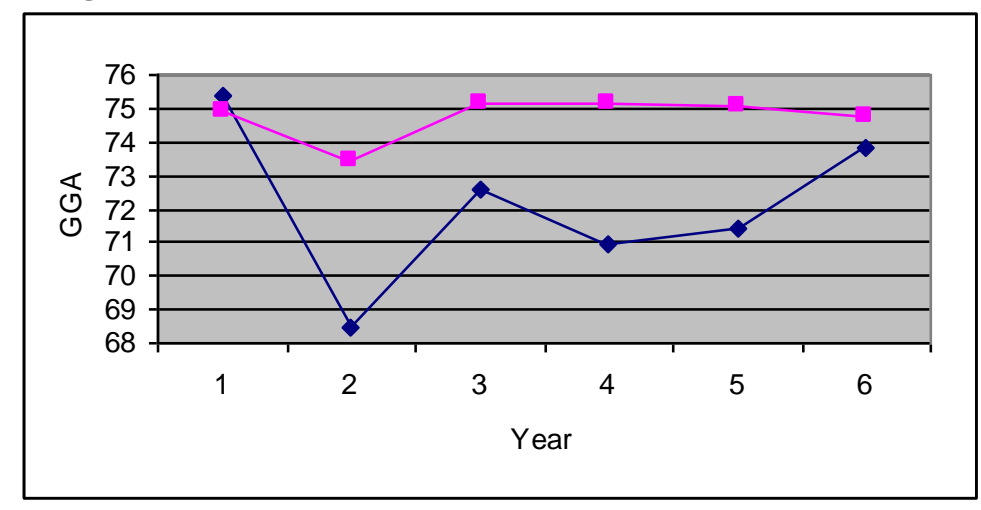

It can also be seen from the graphs that the gap between domestic and international student performance is narrowing over time. This may be attributed to the deliberate initiatives by the institution: the International Education Department in providing a supporting "home away from home" environment for international students and the services of cultural liaisons; Student Services in providing more study space on campus a learning center; and the collaborative initiatives from the Okanagan School of Business in providing subject area student tutors and cultural awareness training to professors.

The data presented and the analysis above has provided answer to Research Question 2: there is a difference in the academic performance of international students and domestic students. While there is a difference it is interesting to note that GGA data shows a similarity. A specific issue - the structural changes implemented by legislation and derived from the political environment has been presented to attempt an explanation of this pattern. However, this situation needs further investigation and is an area identified as warranting further research.

\section{Research Question 3}

Is there a correlation between the percentage of international students in the student body and their academic performance?

Using the Business Grade Averages data, the correlation coefficient is computed between the percentage headcount of international students in the student body and GA of international students, which is 0.1685 . The correlation coefficient between the percentage headcount of international students in the student body and GGA of international students is also computed and is 0.0443 . The two correlation coefficients show a weak positive relation and a nearly zero relation between the percentage of international students in the student body and their academic performance. 
The overall correlation results are not able to reveal the relationship between the percentage of international students in the student body and their academic performance in individual course sections; so this issue is further explored in Research Questions 5 and 6.

\section{Research Question 4}

Is there a correlation between the percentage of international students in the student body and the academic performance of domestic students?

Using the Business Grade Averages data, the correlation coefficient between the percentage headcount of international students in the student body and GA of domestic students is computed and is -0.8318 . The correlation coefficient between the percentage headcount of international students in the student body and GGA of domestic students is also computed and is 0.7003 . The two correlation coefficients show very strong negative and positive relationships respectively.

These results are surprising and difficult to interpret. In fact the overall correlation may not be able to reveal the true relationship between the percentage of international students in the student body and their academic performance in individual course sections. Again, this is issue is further explored in Research Questions 5 and 6.

\section{Research Question 5}

Is there a correlation between the percentage of international students in the student body and their academic performance in certain courses with a relatively large international enrolment?

In order to answer this research question, we divide all course sections into eight groups based on the international student percentage headcount. For example, Group 1 includes those courses in which the interval of international student percentage headcount is between $0 \%$ and less than 5\%, Group 2 between $5 \%$ but less than $10 \%$, and so on. Using the Business Section Averages data, we compute correlation coefficients between the international student percentage headcount and the course average of international students for each of eight groups of course sections. The results are shown in Table 4 and Figure 6 presents the results graphically.

Table 4 Correlation between International Student Percentage Headcount and Section Average of International Students

\begin{tabular}{|lcccccccc|}
\hline \multicolumn{1}{|c}{ Group } & $\mathbf{1}$ & $\mathbf{2}$ & $\mathbf{3}$ & $\mathbf{4}$ & $\mathbf{5}$ & $\mathbf{6}$ & $\mathbf{7}$ & $\mathbf{8}$ \\
\hline Interval of & $0 \%$ & $5 \%$ & $10 \%$ & $20 \%$ & $30 \%$ & $40 \%$ & $50 \%$ & $60 \%$ \\
Percentages & but $<5 \%$ & but $<10 \%$ & but $<20 \%$ & but $<30 \%$ & but $<40 \%$ & but $<50 \%$ & but $<60 \%$ & but $<100 \%$ \\
\hline Correlation & $\mathbf{- 0 . 0 2 4 8}$ & $\mathbf{- 0 . 0 2 7 4}$ & $\mathbf{0 . 0 4 4 9}$ & $\mathbf{0 . 1 1 0 3}$ & $\mathbf{- 0 . 0 0 6 1}$ & $\mathbf{0 . 2 5 8 9}$ & $\mathbf{- 0 . 0 1 6 9}$ & $\mathbf{0 . 0 7 5 5}$ \\
\hline
\end{tabular}

Figure 6 Correlation of International Student Percentage Headcount And Section Average of International Students

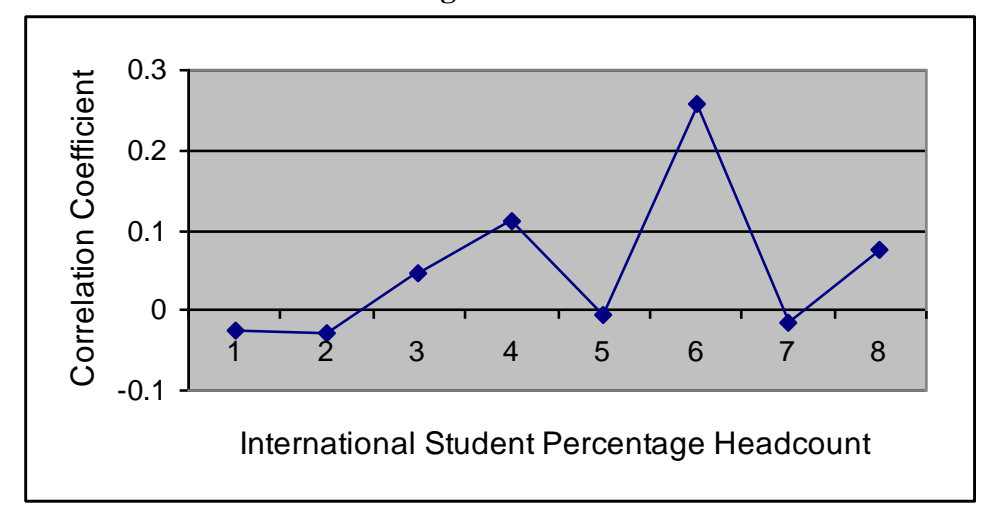

Where there is a very low percentage of international students there is no evidence to suggest that there is a positive impact on the academic performance of international students themselves. The question of whether there is 
an optimal percentage of international students that is most beneficial to international student success still remains unanswered.

\section{Research Question 6}

Is there a correlation between the percentage of international students in the student body and the academic performance of domestic students in certain courses with a relatively large international enrolment?

In order to answer this question, the Business Section Averages data is used to compute correlation coefficients between the international student percentage headcount and the course average of domestic students for each of eight groups of course sections. The results are shown in Table 5 and Figure 7 presents the results graphically.

Table 5

Correlation Between International Student Percentage Headcount and Section Average of Domestic Students

\begin{tabular}{|lcccccccc|}
\hline \multicolumn{1}{|c}{ Group } & $\mathbf{1}$ & $\mathbf{2}$ & $\mathbf{3}$ & $\mathbf{4}$ & $\mathbf{5}$ & $\mathbf{6}$ & $\mathbf{7}$ & $\mathbf{8}$ \\
\hline Interval of & $0 \%$ & $5 \%$ & $10 \%$ & $20 \%$ & $30 \%$ & $40 \%$ & $50 \%$ & $60 \%$ \\
Percentages & but $<5 \%$ & but $<10 \%$ & but $<20 \%$ & but $<30 \%$ & but $<40 \%$ & but $<50 \%$ & but $<60 \%$ & but $<100 \%$ \\
\hline Correlation & $\mathbf{0 . 0 4 9 7}$ & $\mathbf{- 0 . 1 0 7 0}$ & $\mathbf{- 0 . 1 1 1 7}$ & $\mathbf{0 . 0 0 5 7}$ & $\mathbf{- 0 . 0 0 3 3}$ & $\mathbf{0 . 1 4 9 6}$ & $\mathbf{0 . 1 2 2 0}$ & $\mathbf{- 0 . 1 4 4 3}$ \\
\hline
\end{tabular}

Figure 7

Correlation between International Student Percentage Headcount and Section Average of Domestic Students

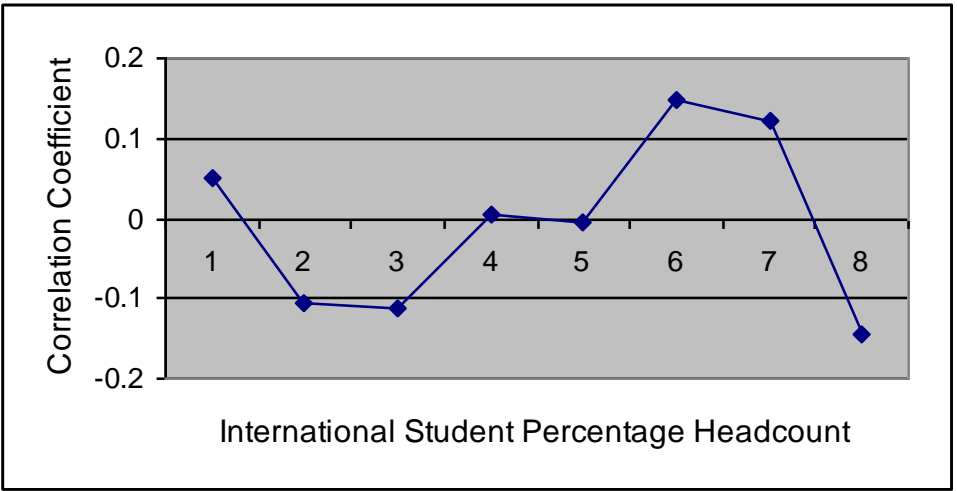

In addition, the Business Section Averages data is used to compute correlation coefficients between the international student percentage headcount and the course average of total students for each of eight groups of course sections. The results are shown in Table 6 and Figure 8 presents the results graphically.

Table 6 Correlation of International Student Percentage Headcount and Section Average of Total Students

\begin{tabular}{|lcccccccc|}
\hline Group & $\mathbf{1}$ & $\mathbf{2}$ & $\mathbf{3}$ & $\mathbf{4}$ & $\mathbf{5}$ & $\mathbf{6}$ & $\mathbf{7}$ & $\mathbf{8}$ \\
\hline Interval of & $0 \%$ & $5 \%$ & $10 \%$ & $20 \%$ & $30 \%$ & $40 \%$ & $50 \%$ & $60 \%$ \\
Percentages & but $<5 \%$ & but $<10 \%$ & but $<20 \%$ & but $<30 \%$ & but $<40 \%$ & but $<50 \%$ & but $<60 \%$ & but $<100 \%$ \\
\hline Correlation & $\mathbf{0 . 0 4 1 4}$ & $\mathbf{- 0 . 1 1 6 2}$ & $\mathbf{- 0 . 1 1 0 2}$ & $\mathbf{0 . 0 2 0 7}$ & $\mathbf{- 0 . 0 2 1 1}$ & $\mathbf{0 . 2 0 6 1}$ & $\mathbf{0 . 0 3 3 0}$ & $\mathbf{- 0 . 0 2 6 4}$ \\
\hline
\end{tabular}

A very low percentage of international students does not appear to have any positive impact on student performance - neither on domestic students nor on the total student body. Again, whether there is an optimal percentage of international students that promotes the academic performance of domestic students and all students is not evident. The question remains unanswered from this research. 
Figure 8

Correlation between International Student Percentage Headcount and Section Average of Total Students

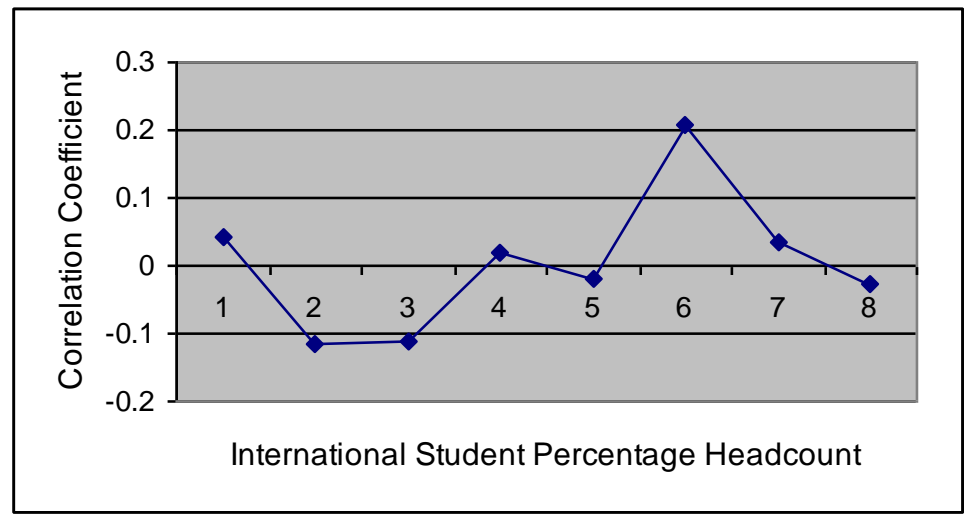

\section{DISCUSSION AND LIMITATIONS}

While the situation at the Okanagan School of Business is similar to other institutions in that the views expressed anecdotally is that international students do not perform as well as domestic students, the study is consistent with the literature that when analyzing the data, the academic performance of international students does not vary substantially from that of their domestic contemporaries.

This study has reviewed the data for a single program within a single institution and therefore the results cannot be generalized to apply to a broader context. Within the single institutional context, expanding the analysis over a longer time frame could also serve to strengthen the findings as data was only available for a limited number of years.

No work was done to determine whether the assessment methods used in the courses were designed to be culturally equivalent. Based on the literature (de Vita, 2002) the results of the study could be confounded due to this issue.

Additional research could be undertaken to relate assessment methods with academic performance and also to investigate further the comparative assessment tools used in lower level and higher level courses. The methodology developed by Lebcir, Wells and Bond (2008) to identify the factors affecting performance in project management courses as identified by the international students themselves could be replicated in business management courses at Okanagan College. Results from such a study could specifically inform the implementation of methods to improve teaching and learning.

Unlike the study of tertiary level accounting students (Harnett, Romcke and Yap, 2004), the results at the Okanagan School of Business do show evidence of an acculturation effect - the performance of international students improved with the passage of time. Further research is also warranted on the relationship between levels of English proficiency and academic performance in the specific context. The acculturation effect may be more in evidence in the smaller student centered environment of a community college than in large universities, particularly in one in which many supporting initiatives have been implemented. This area warrants further research.

This study investigated the academic performance of international students in relation to the total percentage of international students. This is an area that warrants further research as the data is inconclusive in this case. While there is no evidence to suggest that the percentage of international students in a course is related to the academic performance of either the international or domestic students, whether there is an optimal range for the percentage of international students in business courses cannot be established from this study and is another area identified for future research. 
This paper has been prepared based on quantitative methods only. Qualitative research methodologies such as focus groups are normally better able to clarify complex, multi-dimensional issues and future research should incorporate a broader range of methodologies. The conclusions from this study are summarized in the final section.

\section{CONCLUSIONS}

Using time series data, this study shows that the domestic student academic performance is generally better than the international student performance but the gap is significantly narrowing as the international student performance is improving overtime. This is supported by the data analysis but the cause of that improvement cannot be definitively confirmed by the current study. It is possible that an acculturation effect exists in business education due to the environmental and institutional context of the program. While the current observations are based on only six years, the administration of Okanagan College and the Okanagan School of Business would be well advised to continue with the current support initiatives.

While there are differences in the academic performance of domestic and international students, and in most instances domestic students achieved higher GA and GGA, it is interesting that the data shows that in year one the GGA for international students was actually higher than that for domestic students. The factors contributing to this result warrant further study.

No correlation between the percentage of international students in the student body and their academic performance could be established. Nor was any correlation evident between the percentage of international students in the student body and the academic performance of domestic students. These two issues remain outstanding and warrant future study but also have the potential to impact the admissions policy of the institution. There is a mix of positive and negative correlation statistics over the years of the study. A stronger indication of the impact of percentages of international students and the academic performance of both international and domestic students should be established to inform administrative decisions relating to international student recruitment and admission.

\section{REFERENCES}

1. Blount-Lyon, S. 2008, International Study Shouldn't Be Elective, Inside Higher Ed December 19

2. Bie, KN, 1976, Norwegian Students at British Universities - A Case Study of the Academic Performances of Foreign Students, Scandinavian Journal of Educational Research, Vol 20 Iss 1 pp 1-24

3. deVita, G, 2002 Cultural Equivalence in the Assessment of Home and International Business Management Students: a UK exploratory study, Studies in Higher Education Vol 27, No 2

4. Eddey, P, Baumann, C., 2008, Graduate Business Education: Profiling Successful Students and Its Relevance for Marketing and Recruitment Policy, Journal of Education for Business, Heldref Publications

5. Foster, P.B. 1965, Management Perspective: Predicting Academic Performance of Foreign and NonForeign Students in a Graduate Business School, Management Perspective, Academy of Management, pp319-323

6. Hartnett, N, Romcke, J., Yap, C, 2003, Student Performance in tertiary-level accounting: an international student focus, Accounting and Finance, Australia and New Zealand, Blackwell

7. Lebcir, RM, Wells, H, Bond, A, 2008, Factors affecting academic performance of international students in project management courses: A case study from a British Post 92 University, International Journal of Project Management, Kidlington, April 2008 Vol 26 Iss 3 pg 268

8. Okanagan College, 2005, Strategic Plan http://www.okanagan.bc.ca/Assets/Departments+(Administration)/Public+Affairs/Designing+our+Future/F inal+Strategic+Plan.pdf?method=1 [Accessed January 7, 2009]

9. Smith, J., Cooke, J., Gilchrist, K., 2008, ESL Student Success Review, Okanagan College, BC Canada 